\title{
MedienPädagogik
}

Zeitschrift für Theorie und Praxis der Medienbildung

Themenheft Nr. 11: Media Education:

Stand der Medienpädagogik im internationalen Raum

Herausgegeben von Heinz Moser

\section{Editorial: Media Education: Stand der Medienpäda- gogik im internationalen Raum}

Heinz Moser

Seit der Gründung dieser Zeitschrift wurde der Beirat verstärkt auch international ausgebaut. Dies war schon deshalb notwendig, weil die vermehrt erscheinenden englischen Beiträge nicht allein aus deutschsprachiger Sicht begutachtet werden sollen. In der vorliegenden Ausgabe sollte der erweiterte Beirat eine Möglichkeit erhalten sich vorzustellen - nicht persönlich, sondern mit seiner Einschätzung der Medienpädagogik im eigenen Land. Dieser Anfrage sind Medienpädagogen aus verschiedenen Ländern gefolgt - von Österreich bis zu Grossbritannien und den USA.

Dabei fällt eine gewisse Zwiespältigkeit zur Situation der Medienpädagogik auf: Auf der einen Seite wird betont, wie der rasante technologische Wandel die Situation der Medienpädagogik in den letzten Jahrzehnten verändert hat. Johannes Fromme beschreibt in seinem Beitrag diesen Wandel im Hinblick auf die Mediensozialisation - bis hin zu Positionen, welche Aspekte einer Selbstsozialisation in den Vordergrund stellen. Damit stellen sich Anschlussfragen - wie diejenige von Fromme, was die Freisetzung der Individuen in der soziokulturellen Sphäre bedeute, wenn diese mit dem wachsenden Einfluss anonymer Instanzen wie den Medien konfrontiert sind. Oder es wäre auf David Buckingham zu verweisen, der in seinem Beitrag die Frage stellt, inwieweit der Begriff des medienkompetenten Kindes selbst ein Konstrukt darstellt. Für ihn sind beide Auffassungen problematisch und romantisierend - die traditionelle Konzeption des unschuldigen Kindes genauso wie jenes, welches das weise und medienkompetente Kind feiert.

Es sind also «grosse» Themen die heute der Bearbeitung durch den medienpädagogischen Diskurs warten. Damit kontrastiert indessen die in mehreren Beiträgen geäusserte Auffassung, dass die Medienpädagogik ein Schattendasein friste bzw. noch am Anfang stehe. So beginnen Douglas Kellner und Jeff Share mit der Bemerkung, dass die Medienpädagogik in den USA weit weniger avanciert sei wie in anderen englischsprachigen Länder (z.B. in Grossbritannien, Kanada und Australien). Für Österreich betonen Ingrid Paus-Hasebrink und Brigitte Hipfl, dass es eine Vielzahl von Angeboten und Konzepten gebe, aber dass dennoch eine institutionelle Verstärkung notwendig sei. Das von mehreren Autoren aufgespannte Kaleidoskop in acht Bildern belegt sowohl diese Vielfalt, stellt aber implizit auch die Frage nach der Konzentration und weiteren theoretischen Fundierung. Mit dieser Problematik steigt auch Gerhard Tulodziecki ein, wenn er auf die ausserordentlich grosse Begriffsvielfalt aufmerksam macht, welche in der Medienpädagogik vorherrschend ist. Dennoch macht sein Beitrag auch deutlich, dass mit den bescheidenen Mitteln, über welche die Medienpädagogik verfügt, auch einiges erreicht wurde - und dass sich weitere Chancen bieten, wenn die Entwicklungen im Medienbereich konstruktiv aufgenommen werden. 